\title{
A SNAPSHOT OF THE CANADIAN ENGINEERING EDUCATION SYSTEM: REFLECTIONS FROM AN EMERGING SCHOLAR TRYING TO SUPPORT NATIONAL CURRICULUM CHANGE
}

\author{
Stephen Mattucci \\ Canadian Engineering Education Challenge (CEEC), McMaster University \\ stephenmattucci@engineeringchangelab.ca
}

\begin{abstract}
The Canadian Engineering Education Challenge (CEEC) is an initiative with the goal of 'developing a national collaboration to target engineering curriculum to graduate students who will be eminently prepared to take on the challenges of the future'. The National Coordinator performed a scan of the education system across Canadian engineering programs to determine existing initiatives, and common challenges. The objectives of this work are: 1. Identify needs and challenges of the Canadian Engineering Education system, and 2. Identify challenges and opportunities in providing support to curricular change initiatives.
\end{abstract}

This work is conceptually framed and driven through the Coordinator's perspectives, assumptions and goals, using an action research framework. A qualitative inductive thematic analysis is used to identify common themes and trends from across visits and conversations with over 60 individuals from 14 institutions. A secondary goal of this work is to share the process, lessons learned, and personal reflections, with those who have contributed to generating the data, and others entering into the field of Engineering Education.

Several trends emerged from the data, which elucidate needs and challenges. These include: distinct roles in the system, curricular initiatives relating to non-technical skills and design spine, challenges associated with Engineering Education Research and the Scholarship of Teaching and Learning, the impact and inertia of culture, modeling and instructor training related to non-technical skills, funding promotes change, and the importance of terminology and shared understanding.

Considerations became apparent which may inform how to best support individuals and the system. These include: the need to align with the existing priorities of others, the desire for engineering educators to learn from each other, the power of culture, and incentives to promote engagement.

This work will serve to identify potential opportunities for the CEEC to leverage collaboration between institutions with common alignment, as well as important considerations to be incorporated for the CEEC to maximize impact. Finally, this work hopes to provide valuable insight to others who wish to engage more deeply in Engineering Education.

Keywords: Action Research, qualitative research, engineering education, system scan, challenges and opportunities, Canadian Engineering Education Challenge

\section{BACKGROUND}

The Canadian Engineering Education Challenge (CEEC) was formed as a sub-initiative of the Engineering Change Lab (ECL, [1]), to address the needs of the postsecondary training of engineers, under the broader context of maximizing the greater potential of the engineering profession. The initial lab members involved in the CEEC initiative were primarily leaders from both industry and academia. The initial high-level goal was to:

"Address the current shortcomings of the profession by enhancing the preparation of graduates from engineering programs through alignment of their education with the priority needs of industry and the Canadian economy and by building on the strengths and aspirations of graduates. " [2]

The approach was to develop a collaborative network of institutions working on engineering curriculum redevelopment informed by input from a range of academic, industry and student stakeholders. The efforts would be driven through a strong community of likeminded people who are open to experimentation, want to measure the results of their work, and learn from each other.

Members of the CEEC focused their energy toward the creation of a full-time National Coordinator position to manage the project and forward the goals of the CEEC. Funds were secured through the National Council of Deans of Engineering and Applied Sciences (NCDEAS), from ten institutions across Canada. One of the first tasks of the National Coordinator was to perform a scan of the 
education system across Canadian engineering programs to determine initiatives already underway, and what challenges are most common, as self-identified by educators at each institution. Identifying commonalities and alignment would provide avenues to leverage collaborative efforts across several institutional contexts for more widespread adoption of curricular change innovations.

This paper reports on the interim findings from early data analysis with engineering educators across fourteen institutions. In addition, this paper also provides a reflective account on the process to date, including the development of an emerging conceptual framework to inform national-level enhancement of engineering curricula in Canada. This includes discussions of the CEEC initiative model as a mechanism for achieving this, highlighting next steps and future priorities. Therefore the specific objectives of this work are to:

1. Identify several needs and challenges of the Canadian Engineering Education system, and

2. Identify challenges and opportunities in providing support to curricular change initiatives.

\section{CONCEPTUAL FRAMING}

For this work, I use an interpretivism theoretical approach and more specifically, an action research framework is used - a disciplined inquiry conducted by and for those taking the action [3]. In this case I am identifying the needs of the Engineering Education system in Canada, while also using the findings to provide direction for opportunities for support. The interpretivism approach is commonly referred to as 'in the fishbowl', where in this case I was visiting and interacting with engineering educators to determine what interventions I could provide, that may result in a positive contribution. The fishbowl analogy conveniently also represents the siloed environment in which most institutions operate, with few interactions across institutional boundaries - one of the key aspects the CEEC aspires to change.
This work is framed and driven through my own perspectives, assumptions and goals - which are related to my aforementioned understanding of the CEEC and role as the National Coordinator, and my relevant background and experience. Having recently completed a Ph.D. in a technical engineering field (biomedical engineering), I elected to transition into the emerging Engineering education field. I had completed several formal education training sessions (e.g. instruction, facilitation, peer review), been involved in pedagogical and curricular initiatives, in addition to publishing and presenting at CEEA.

In beginning this work, I was unfamiliar with the differences between engineering research and educational research, and the need to situate the work within an appropriate conceptual framework, and selecting appropriate qualitative research approaches. My perspectives of the field of Engineering Education had been framed primarily through my experiences as a student. I was aware of the governing accreditation body, but not the overarching motivations behind the policies, or the tensions between theory and practice, or technical vs. complementary competencies. However, I had felt over the duration of my education in engineering, the world around me had changed rapidly enough that many skills I learned (especially related to technology) were no longer relevant, and that education needed to shift to better prepare students for an unknown future. I was not aware that 'change management' was distinct discipline, or the difficulties of implementing change in an academic context.

As a recent graduate and emerging scholar in this field, I assumed an open perspective as I searched for opportunities to make positive change. Not many educators have the opportunity to tour across the country specifically to learn about existing innovative approaches and major challenges. Therefore, the intent was to use the findings from these visits to determine how the CEEC may best support national curricular change, but to also share the process, observations, and lessons learned along the way, with those who contributed to generating the data.

Table 1: Institutions participating in the system scan.

\begin{tabular}{|lll|}
\hline Participating Institutions & & \\
\hline - Conestoga College & - University of British Columbia* & • University of Saskatchewan \\
- McGill University* & - University of Calgary* & • University of Toronto* \\
- McMaster University*^ & - University of Guelph & $\bullet$ University of Waterloo* \\
- Memorial University* & - University of Manitoba* & - Western University* \\
- Queen's University* & - University of Prince Edward Island \\
\hline
\end{tabular}

*funding institution, ^host institution 
Table 2: Identified common roles in the engineering education system (alphabetical order)

\begin{tabular}{|c|c|}
\hline Role & Description \\
\hline $\begin{array}{l}\text { 1. Administrative } \\
\text { Support Staff }\end{array}$ & Support the entire community within an institution. They are often gatekeepers. \\
\hline 2. Associate Deans & Academic leadership with a specific focus (e.g. research, academic, teaching) \\
\hline 3. Collaborators & $\begin{array}{l}\text { Work outside of the Engineering Education system, however can work together in a mutually } \\
\text { beneficial towards simultaneous goals }\end{array}$ \\
\hline $\begin{array}{l}\text { 4. Curriculum } \\
\text { Innovators }\end{array}$ & Coordinate and implement curriculum change strategies \\
\hline 5. Deans & Manage institutional faculty, and establish vision \\
\hline 6. Industry & Industry portals in education: Engineer-in-Residence positions, capstone coordinators \\
\hline $\begin{array}{l}\text { 7. Instructors } \\
\text { and }\end{array}$ & Responsible for developing and teaching courses \\
\hline 8. Faculty & $\begin{array}{l}\text { Same duties as instructors, with a stronger cultural and procedural influence on a } \\
\text { faculty/department }\end{array}$ \\
\hline 9. Post-docs & $\begin{array}{l}\text { Technical PhD graduates with a specialization in education, contributing in various ways. A } \\
\text { relative new role. }\end{array}$ \\
\hline Stakeholders & $\begin{array}{l}\text { Any person, place, or thing who stands to benefit from better engineering graduates. Including } \\
\text { industry, the general public, and society as a whole }\end{array}$ \\
\hline 11. Students & Those who are being educated in an engineering program \\
\hline 12. Student Educators & Undergraduate, or graduate students who are involved in educating other students \\
\hline
\end{tabular}

\section{METHODS}

The methodology I employed was a qualitative inductive thematic analysis to identify common themes from engineering programs across Canada. This qualitative approach allows for themes to emerge from the richness and depth of the data, rather than testing for specific hypothesis. I organized visits and conversations with Engineering Education contacts at 14 institutions (Table 1), through: the funding deans, an announcement through NCDEAS, or through any individuals who initiated contact. No institutions were denied participation.

Over the course of 6 months (April - October, 2018), I visited and had discussions with over 60 engineering educators, who self-identified relevant initiatives and challenges. I diligently made notes from all conversations, and transcribed within two weeks. The notes were read and coded for relevant themes, then following three months, recoded again (two-stage coding). The codes identified in the data fell into the broad categories: HighLevel, Curriculum, Complementary, Institutional, and Teaching and Learning (specific codes and descriptions are found in Appendix A). The descriptors for the analysis are by institution.

The text was coded and analyzed using Dedoose qualitative analysis software (Version 8.1.8). The codes were primarily analyzed for: prevalence to inform which themes were most common, and for co-occurrences to identify potential trends. Several findings emerged through processing the data in this approach.
Of note, unless explicitly stated, any text referred to in quotations are not verbatim quotes, but paraphrasing of the messaging. Verbatim quotes were not included out of privacy, since research ethics were not obtained.

\section{RESULTS}

The trends which emerged from the themes serve to address the first objective of this work: identify several needs and challenges of the Canadian Engineering Education system. The findings listed below encompass seven major trends regarding the engineering education system.

\subsection{Respondent Categories by Institutional Role}

As the visits and meetings progressed, it became evident that people shared distinct characteristics with respect to their roles both at their own institution and within the system as a whole. The roles identified are detailed in Table 2. It is important to note that individuals are not limited to one role, and in fact many take on multiple roles in their work.

\subsection{Non-Technical Skills and Design Spine}

Two of the most common themes discussed, which were often intertwined, were: non-technical skills embedded in core curriculum, and design spine implementation. Often referred to differently, many are aware of the need to better develop students' nontechnical / professional / transferable skills. There is plenty of evidence [4]-[7] regarding these being the underdeveloped skills that employer's desire, yet 
integrating these into the curriculum in a meaningful way is still challenging. For example, simply having students do a presentation in a course does not necessarily help them learn how and why they should improve their communication skills. Another common curricular focus was around implementing a Design Spine: a curricular structure within a program to progressively develop design-related competencies over several years. Often these are intertwined, as design is a more obvious avenue to incorporate non-technical skills, compared to traditional technical courses. Given the widespread interest and energy related to these curriculum pursuits, they appear to be an ideal opportunity for collaborative efforts.

\subsection{Barriers and pathways associated with Scholarship of Teaching and Learning}

Many engineering educators are interested in more deeply engaging in Engineering Education, however they often do not know how or where to start. Some individuals confessed they feel the work is tedious, and doesn't prove anything in a convincing way (which also prompts the question: what evidence would be convincing to this community?). It is an intimidating new space - an entirely new field with unfamiliar methods and approaches. Academia systemically fosters a mindset where one spends countless years becoming the foremost expert in their domain, intimately familiar with the state of knowledge and best practices in the field. Naturally it can be challenging to then voluntarily enter a space in which they are now the novice, in an unfamiliar field with different methodologies and ways of thinking.

To engage more deeply in Engineering Education often requires additional capacity, and/or expertise, that educators simply do not have. If someone is redesigning a course, obtaining research ethics to publish results openly, is a considerable amount of extra work, especially when the educator's primary focus to develop the course. This is exemplified when the type of research is unfamiliar to begin with. Several individuals discussed data that was gathered to inform a curricular innovation, yet was never made public despite the potential value to others. This scholarship aspect of making work open and public does may not align with existing priorities, and also may not be valued towards career advancement criteria.

Related to both unfamiliarity in the field, and work required, one specific theme frequently arose: assessment of education initiatives is challenging. Sound research involves the assessment of one's interventions, to determine their efficacy. Without appropriate assessment, otherwise interesting findings may not be disseminated. Assessment is a broader concern as well, as education best practices are more easily shared in the community when efficacy is demonstrated.

To promote Engineering Education research, more pathways to engage and learn, and support are required.
Many engineering educators are engaged in Engineering Education as they prefer teaching over (their traditional technical) research - yet there is a stigma that perceives Engineering Education scholarship strictly as research. Some people stated this explicitly, and I believe it also relates to parallels drawn to technical research fields, and familiar quantitative methods. Some educators mentioned the need to validate other practices in the field as wellrecognized scholarly activities. Activities such as the peer review of others practices - which in this case is teaching and not research.

Table 3. Continuum of SoTL [8],[9]

\begin{tabular}{|c|c|}
\hline Level of inquiry & Attributes of that level \\
\hline $\begin{array}{l}\text { Level 1: Excellent } \\
\text { teaching }\end{array}$ & Good content and teaching methods \\
\hline $\begin{array}{l}\text { Level 2: Scholarly } \\
\text { Teaching }\end{array}$ & $\begin{array}{l}\text { and classroom assessment and } \\
\text { evidence gathering, informed by best } \\
\text { practice, inviting of collaboration and } \\
\text { review }\end{array}$ \\
\hline Level 3: SoTL & $\begin{array}{l}\text { and is public, can be built upon, and } \\
\text { open to critique. Involves inquiry and } \\
\text { investigation, particularly about } \\
\text { student learning (focus on "what" or } \\
\text { "how much"). }\end{array}$ \\
\hline $\begin{array}{l}\text { Level 4: Rigorous } \\
\text { Research in EngEd }\end{array}$ & $\begin{array}{l}\text { Like SoTL, but with: } \\
\text { 1. Research question (focus on } \\
\text { "why" or "how" of learning) } \\
\text { 2. Interpreting results in light of } \\
\text { theory (learning, pedagogical, } \\
\text { social) } \\
\text { 3. Appropriate study design and } \\
\text { methods, allows to hold up } \\
\text { against scrutiny }\end{array}$ \\
\hline
\end{tabular}

The "teaching vs. research" debate has waged on for long before Boyer (1990) introduced four interdependent dimensions of scholarship: discovery, integration, application, and teaching. 'Scholarship of Teaching and Learning' (SoTL) has since been placed on a continuum with respect to the level of inquiry involved [9]. In order to progress in level of inquiry towards 'rigorous research in Engineering Education', Streveler, Borrego, and Smith (2007) suggest one should be familiar with three paradigm shifts. First, the differences between engineering research (often implicit theory and methods) and educational research (apply appropriate theoretical/conceptual frameworks, methods, and approach). Second, the difference between assessment questions ("what" or "how much" learning occurred) and research questions ("why" or "how" did learning occur). Third, the distinct differences between the levels of inquiry discussed in Table 3. 


\subsection{The Impact and Inertia of Culture}

Culture was the most prevalent thematic code applied, and its importance at any given institution cannot be understated. Culture can be viewed to exist in four frames: political, structural, symbolic and human resources[8]. This makes breaking down the specific role of culture in any instance very complex even at the institutional level, let alone at the national level. An example at one institution of how culture is fostered in the structural context: the Teaching and Learning Centre (TLC) is located in the building adjacent to engineering resources are easily accessible to educators, promoting a strong relationship with the TLC.

Table 4. The four-frame model of understanding organizations. Adapted from [11]

\begin{tabular}{|l|l|}
\hline Structure & Human Resources \\
Rules, goals, policies, & Needs, skills, relationships, \\
technology & social capital \\
The organization is $a:$ & The organization is $a$ : \\
Factory & Family \\
\hline Political & Symbolic \\
Power, conflict, & Meaning, ritual, ceremony, \\
competition & stories, heroes \\
The organization is $a:$ & The organization is $a:$ \\
Jungle & Theatre \\
\hline
\end{tabular}

The inertia of culture presents a barrier in the face of curricular change. Many academics are not convinced there is a problem with the current approach of educating engineers, and generates responses such as: 'the process works', and 'why fix what isn't broken'. Some are immediately defensive before even discussing curricular change - 'Don't dilute the technical competencies. Don't make engineers into sociologists'. Unsurprisingly, many people voiced concern of the typical challenges associated with progressing education initiatives through the procedural steps at their institutions.

Throughout visits, three widely reported approaches to shift culture are from administrative leadership, new faculty hires, and student pressure. Administrative leadership through the Dean's Office (Dean, Associate Deans, Chairs, etc.) sets the mission and vision of the faculty, which results in widespread value placed on the importance of teaching and learning. Through the implementation of teaching chairs, one institution mentioned that "when you come from the Dean's office, what you say and do is interpreted differently" (political frame). Since the culture is so strongly influenced by those present, the hiring of new faculty was mentioned frequently as a mechanism to promote culture change, and with the associated moniker of 'new blood' (human resource frame). Students also have a tremendous power to shift the culture. One institution reported of innovative approaches used by one instructor that were then requested by students in other classes.

Another way of promoting the culture of SoTL in Engineering, which demonstrated positive results at multiple institutions was showcasing Engineering Education and modeling SoTL through initiatives and events (symbolic frame). The eLATE (enhancing Learning and Teaching in Engineering) initiative at McGill promotes SoTL through a variety of approaches including a Teaching and Learning week where instructors have an open door policy to share best practices, and social opportunities. Calgary held a daylong EngEd Forum, where educators were encouraged to deliver their upcoming CEEA and ASEE presentations, and receive feedback from their peers, all while spreading SoTL awareness throughout the faculty. The event also included a vigorous planned lunch discussion, and a keynote workshop. Several attendees admitted this was their first ever talk focused on education - proof that this event fosters a safe and welcoming environment.

\subsection{Modeling and Instructor Training relating to Non-technical skills}

One person I met with said: "We talk about teamwork, but we don't practice this as academics". Other institutions took one step further to suggest that many engineering instructors are lacking in non-technical competencies themselves, and therefore don't properly model these competencies, let alone being able to teach these skills. Scheduling also models the value placed on the skills learned in these types of courses. Courses in communication scheduled late at night and/or "whatever year there's space in a program' symbolizes the mentality of privileging the 'core technical curriculum'. However, one person remarked at how students in first year had a bias devaluing the importance of non-technical skills, so it is entirely possible that many students enter undergraduate with preconceived notions of the importance of different skill sets - which further begs the question of when and where these biases were developed. Further, perhaps one of the more common examples is the common reference to these skills as "soft skills", where the label implicitly devalues the importance.

\subsection{Funding Promotes SoTL}

I noticed that the progressive culture at several institutions was closely associated with large-scale education initiatives. Interestingly most of these initiatives were developed through some funding avenue. Queen's University hosts several teaching and learning postdoctoral fellows as well as a dedicated engineering teaching and learning centre; University of Waterloo runs the IDEAs clinic interwoven throughout curriculum; University of Calgary fostered a collaborative interdisciplinary relationship to implement a teamwork 
tool; UBC was able to overhaul the core engineering component of the first-year curriculum; and the eLATE initiative at McGill University serves as the Engineering Education hub of the faculty. Several people that hold NSERC Design Chair positions have been able to leverage funding towards education initiatives, however, since these positions will no longer be offered, it remains to be seen if the upcoming NSERC Alliance grants may support educational initiatives.

Unfortunately, but unsurprisingly, the other common aspect mentioned with respect to funding was how the lack of availability, and lack of advocacy success serves as a tremendous barrier in the system. The positive results demonstrated through Teaching and Learning initiatives across the country, driven by funding sources is strong evidence to further support the need for more funding avenues in Canada.

\subsection{Importance Shared Understanding}

This process involved a significant amount of communicating with Engineering Educators, and many others related to the system, which has demonstrated the importance of terminology, language, and impact on a shared understanding. The importance of developing communication skills in students is constantly emphasized, yet sometimes we fail to recognize this importance in our own contexts. The engineering education system is an interdisciplinary field, where people bring their unique epistemologies and understandings from different backgrounds miscommunication is to be expected in any interdisciplinary pursuit! Some reported examples include: understanding the difference between 'teaching' and 'learning'; or different interpretations of 'capstone' from industry and academic perspectives; or differences in what falls under the umbrella of 'curriculum'; or are 'graduate attributes' the specific competency students learn, or the accreditation board's quantified criteria? Some of these could serve to be more broadly defined, however the underlying concept relies on finding and ensuring a shared understanding between parties.

\section{DISCUSSION}

\subsection{Evolving Conceptualization of Curricular Change in Engineering Education}

While identifying the needs and challenges in the system such as those related to research and SoTL, systemic culture barriers, and the meaningful incorporation on non-technical skills, other trends began to emerge as overarching lessons learned during the process. These lessons learned are directly relevant to the second goal of this work, to determine important considerations to best support these needs of individuals and the system
One of the biggest takeaways is the need for alignment of priorities between engineering educators in order to foster collaboration opportunities. People were very forthcoming to share their main priorities and what they were working on, but were relatively reserved when discussing opportunities for collaboration - perhaps this was seen as more work on their plates. People are busy. They agree with the importance of the pursuits of the CEEC, however their own commitments are their priorities. Rather than ask to take time away from priorities, the CEEC initiative needs to bring people together where there is alignment between existing goals. People want to learn from each other. Educators voiced a strong appetite to see and learn from what everyone else is doing. In an emerging landscape in Canada, many do not feel they are 'true experts' or 'leaders' with respect to focused areas. However, many are contributing to similar areas - e.g. many are doing work related to design spine, but no institution regarded themselves as the leader in the space.

Culture is powerful, and has enormous inertia at each institution. The influence of culture came up in discussions at every institution. In order for change strategies to be effective, they should consider all four organizational frames discussed earlier. However, an effective change strategy at one institution may not be as effective at other institutions due to the differences in each of the four frames. Therefore, in order to support curricular change at the national level, there is a need for creatively combining approaches from multiple categories of change strategies [12].

People will engage if the incentives are right. This is broad, however two widespread and related incentives include: funding, and recognition of SoTL. People will engage if they can secure funding, however, currently most funding avenues are limited to institutional mechanisms, as there are currently no large-scale, designated avenues for supporting Engineering Education research. People will also engage if it acts to further their careers. Teaching-stream faculty appointments are becoming more common across Canada, however tenure and promotion criteria are inconsistent across institutions, with limited pathways and opportunities for educators to demonstrate SoTL contributions that are recognized.

\subsection{Reflections}

Through many conversations I learned of the importance of identifying a real need, versus proposing a solution. This drove visits and discussions, with a focus on priorities and challenges at each institution, which helped gain a breadth of information across the visits. This approach framed the needs of the system more completely than if I was proposing solutions from the start, where findings would have been contextualized within the frame of the proposed solutions. 
Additionally, the Engineering Education community in Canada is a welcoming and supportive environment for those seeking to engage. As I met people across the country, I found it very interesting how many engineering educators had stories for how they become engaged. So many unique backgrounds and pathways, yet it seemed everyone had somehow found the same door to a secret garden, producing a vibrant community of people with the best intentions to improve the education of future engineers.

An unanticipated, yet fascinating outcome of this work is the meta-lens of my own process of transitioning from a technical engineering field, integrating into a new field, and engaging with new research methodologies. In many ways, this parallels the observation of colleagues wishing to engage more deeply in Engineering Education. I hope this works serves as a pathway to some, and demonstrates the approach to simply learn by doing, while accepting the associated limitations that accompany any new pursuit. I realize how many things I could have done differently. Yet, I also realize the value of qualitative data when it is presented within its own contextual framing.

In the four months, and three versions of this paper, as I traverse engineering knowledge domains and curricula but also enter into new field of engineering education my lenses and perspectives have shifted and evolved by a startling amount. Each time I reviewed the paper, I could see how much my understanding and interpretation had progressed from the previous iteration, and over such a short time frame. It was disconcerting to finally learn enough in the education space to fully comprehend how much I have yet to learn, which even in itself leads to deep introspection and questioning of my current understanding. This psychological phenomenon is often referred to as the Dunning-Kruger effect, or simply: you don't know, what you don't know. It will be interesting to look back on this in the future, and be able to reference how far I've progressed.

\section{IMPLICATIONS AND NEXT STEPS}

This process has identified aspects of the CEEC in need of clarification. The overarching goals of the initiative have been interpreted differently by many individuals, which are related to assumptions around engagement, and stakeholder expectations. The organizational direction based on initial initiative documentation can be mapped to vision and mission statements as follows:

- Vision - better prepare engineering students to address the needs of the profession/society and the challenges and opportunities of tomorrow

- Mission - to collaboratively promote and develop curricular and pedagogical change efforts
However, the strategy (how to use the mission to achieve the vision) is unclear. The next steps involve establishing a Strategy Team of engaged representatives from involved institutions to provide guidance on the strategic approach.

In order to address the needs of the profession and society, the needs must be defined. From this work, I believe the most appropriate needs for the CEEC to address are: meaningful integration of non-technical professional skills into core curriculum, and barriers and pathways for engineering educators to advance in scholarship of teaching and learning.

\section{References}

[1] "Engineering Change Lab." [Online]. Available: https://engineeringchangelab.ca.

[2] J. Nicell, "Whitepaper - Candian Engineering Education Challenge." Engineering Change Lab, 2015.

[3] R. Sagor, Guiding school improvement with action research. Association for Supervision and Curriculum Development, 2000.

[4] J. O. Grady, "2007 Engineering and Technology Employer Survey."

[5] Royal Bank of Canada, "Humans Wanted - How Canadian youth can thrive in the age of disruption," 2018.

[6] National Academy of Engineering, The Engineer of 2020: Visions of Engineering in the New Century. Washington, D.C.: National Academies Press, 2004.

[7] A. T. Kirkpatrick, S. Danielson, \& T. Perry, "ASME Vision 2030 -- Recommendations for Mechanical Engineering Education," in ASEE Annual Conference and Exposition, Conference Proceedings, 2012, p. 9.

[8] R. Streveler, M. Borrego, K. Smith, "Moving from the 'scholarship of teaching and learning' to 'educational research'" In To Improve the Academy, 25. (p139-149). Bolton, MA. 2007

[9] P. Hutchings, \& L. Shulman, The scholarship of teaching: New elaborations, new developments. Change, 31(5), 10-15. 1999

[10] E. Boyer, Scholarship reconsidered: Priorities of the professoriate. San Fran. Jossey-Bass. 1990

[11] L. G. Bolman and T. E. Deal, Modern approaches to understanding and managing organizations. Jossey-Bass, 1984

[12] M. Borrego, \& C. Henderson, "Increasing the Use of Evidence-Based Teaching in STEM Higher Education: A Comparison of Eight Change Strategies," J. Eng. Educ., vol. 103, no. 2, pp. 220-252, Apr. 2014 


\section{APPENDIX A: CODING FOR THEMATIC ANALYSIS}

\begin{tabular}{|c|c|}
\hline Theme & Definition \\
\hline \multicolumn{2}{|l|}{ High Level } \\
\hline - $\quad$ Existing Initiative & Existing innovative initiatives related to Engineering Education \\
\hline - $\quad$ Project Idea & Potential idea for a project this institute may be interested in collaborating on \\
\hline CEEC Commentary & Higher-level discussions around the function of the CEEC initiative \\
\hline - $\quad$ Challenges / Opportunities & $\begin{array}{l}\text { Explicitly identified challenges this institution faces or potential opportunities to } \\
\text { address a need }\end{array}$ \\
\hline Other Networks & Other existing networks that may be relevant to the CEEC \\
\hline - $\quad$ Stories & Personal stories of pathways into EngEd \\
\hline Reflection & Personal reflections inspired during the discussions \\
\hline Curriculum & Curricular elements related to... \\
\hline - $\quad$ Non-technical Skills Embedded & $\begin{array}{l}\text { Non-technical / professional / transferable skills embedded in core curricular } \\
\text { elements }\end{array}$ \\
\hline - $\quad$ Design Spine & $\begin{array}{l}\text { Design-related competencies are intentionally built upon over a duration of the } \\
\text { program }\end{array}$ \\
\hline - $\quad$ Large Scale Overhauls & $\begin{array}{l}\text { Innovative curricular change strategies, typically larger than the scale of a single } \\
\text { course }\end{array}$ \\
\hline - $\quad$ Society and Larger Role & $\begin{array}{l}\text { Expanding the goals with a more defined focus on the future impact on society, and } \\
\text { the greater role of the engineer }\end{array}$ \\
\hline Leadership & Explicit focus on developing leadership competencies in engineers \\
\hline - Industry/Community Involvement & $\begin{array}{l}\text { Curricular bridges to to the system beyond education: industry and the community. } \\
\text { Typically represented as Capstone projects. }\end{array}$ \\
\hline - $\quad$ Micro-credentials & $\begin{array}{l}\text { Curricular elements are broken down into smaller units, with the intent of more } \\
\text { customizable skill sets. }\end{array}$ \\
\hline Complementary & Explicit focus on ... \\
\hline - Collab/Embedded Non-engineers & Engineers working with non-engineers - at all roles within the system \\
\hline Diversity, Equity, Inclusion & \multirow{3}{*}{ \} Actively developing best practices, } \\
\hline Indigenous Perspective & \\
\hline - $\quad$ Well Being & \\
\hline \multicolumn{2}{|l|}{ Institutional } \\
\hline - $\quad$ Culture & $\begin{array}{l}\text { A broad relationship to the importance of culture. This was further identified to } \\
\text { relevant organizational frames where applicable: Political, Structural, Symbolic, } \\
\text { Human Resources. }\end{array}$ \\
\hline Constraints & Barriers that individuals or institutions face, and beyond (i.e. systemic) \\
\hline - $\quad$ Structure and Process & $\begin{array}{l}\text { Unique considerations relating to operations. Also related to Accreditation } \\
\text { requirements }\end{array}$ \\
\hline \multicolumn{2}{|l|}{ Teaching and Learning } \\
\hline - $\quad$ Establishing SoTL in EngEd & Demonstrations or advocacy which validate Engineering Education practices \\
\hline SoTL & Specific aspects under the broader SoTL umbrella \\
\hline Research & Explicit focus on Engineering Education Research (EER) \\
\hline Community of Practice & Networks of individuals convening under Engineering Education \\
\hline Funding & Avenues of secured funding and advocacy for available funding opportunities \\
\hline Grad Program in EngEd & Developing and advocating for graduate pathways into EngEd \\
\hline - $\quad$ Methods & Detailed pedagogical or curricular approaches \\
\hline Career Path & Opportunities (or lack thereof) \\
\hline - $\quad$ Student Empowerment & Catalyzing and unleashing the student potential \\
\hline - $\quad$ Modeling & Demonstration of appropriate behaviours and best practices \\
\hline - $\quad$ Instructor Training & Further development of competencies in instructors \\
\hline - $\quad$ Relationship with TLC & Utilization of resources available from the Teaching and Learning Centre \\
\hline - $\quad$ Online Resources & Populating and utilizing open resources \\
\hline - $\quad$ Post-docs & Post-doctoral Fellows focusing on Teaching and Learning \\
\hline
\end{tabular}

